\title{
Title:
}

\section{Cold loop polypectomy perforation of a tiny colon polyp}

\section{Authors:}

Alejandro Mínguez Sabater, Cristina Sánchez-Montes, David Ramos Soler, Marco Bustamante-Balén

DOI: $10.17235 /$ reed.2021.8221/2021

Link: PubMed (Epub ahead of print)

Please cite this article as:

Mínguez Sabater Alejandro, Sánchez-Montes Cristina, Ramos Soler David, Bustamante-Balén Marco. Cold loop polypectomy perforation of a tiny colon polyp. Rev Esp Enferm Dig 2021. doi: 10.17235/reed.2021.8221/2021.

This is a PDF file of an unedited manuscript that has been accepted for publication. As a service to our customers we are providing this early version of the manuscript. The manuscript will undergo copyediting, typesetting, and review of the resulting proof before it is published in its final form. Please note that during the production process errors may be discovered which could affect the content, and all legal disclaimers that apply to the journal pertain. 


\section{Cold loop polypectomy perforation of a tiny colon polyp}

Alejandro Mínguez Sabater ${ }^{1}$, Cristina Sánchez-Montes ${ }^{1,2}$, David Ramos Soler ${ }^{2,3}$ and Marco Bustamante-Balén ${ }^{1,2}$

1. Digestive Endoscopy Unit. Hospital Universitari i Politècnic La Fe. Valencia

2. Digestive Endoscopy Research Group. IIS La Fe. Valencia

3. Pathological Anatomy Service. Hospital Universitari i Politècnic La Fe, Valencia.

Corresponding author: Alejandro Mínguez Sabater (alejandromsab11@gmail.com)

Keywords: Polypectomy. Cold loop. Perforation. Polyp. 


\section{Clinical case:}

We report the case of a 61-year-old woman having corticoid treatment with corticosteroids for polyarthralgia, who underwent a post-polypectomy surveillance colonoscopy, identifying a 5-mm diameter, flat-elevated polyp in the proximal transverse colon (Paris 0-Ila; Figure 1a ). A block resection was performed with the cold loop technique (25 mm, Olympus model SD-210U-25). A $2 \mathrm{~mm}$ perforation was observed in the eschar (figure 1b) that was closed with 3 clips (figure 2a). The colonic segment was filled with water to confirm the absence of leakage (Figure $2 \mathrm{~b}$ ) and subsequently a tattoo was made $3 \mathrm{~cm}$ distal to the lesion in order to facilitate its location if subsequent surgery was required. The anatomopathological study revealed a hyperplastic polyp (Figure 3). The patient evolved favorably.

\section{Discussion:}

Perforation is the second most frequent complication of polypectomy after bleeding (1). Although several meta-analysis have not described any cold loop perforation (2), some publications have identified anecdotal cases (3). The use of a loop not designed for this purpose, poor colonic compliance when closing the loop, and atypical histology of the lesion (e.g., Schwann cell tumour) have been suggested as possible causes.

Although we suspected thinning / weakness of the intestinal wall as a consequence of corticosteroid treatment, no histological findings were found to support our initial hypothesis. It could also be due to the use of a handle not specifically designed for cold polypectomy, although its use for this purpose is also frequent. 


\section{Bibliography:}

1. Anderloni A, Jovani M, Hassan C, et al. Advances, problems, and complications of polypectomy. Clin Exp Gastroenterol. 2014. 30;7: 285-96 doi: 10.2147/CEG.S43084

2. Shinozaki S, Kobayashi Y, Hayashi Y, et al. Efficacy and safety of cold versus hot snare polypectomy for resecting small colorectal polyps: Systematic review and meta-analysis. Dig Endosc. 2018;30(5): 592-599 doi: 10.1111/den.13173

3. Rodríguez Sánchez J, Sánchez Alonso M, Pellisé Urquiza M. The "bubble sign": a novel way to detect a perforation after cold snare polypectomy. Endoscopy. 2019;51(8): 796-797 doi: 10.1055/a-0881-2856

\section{Figures:}

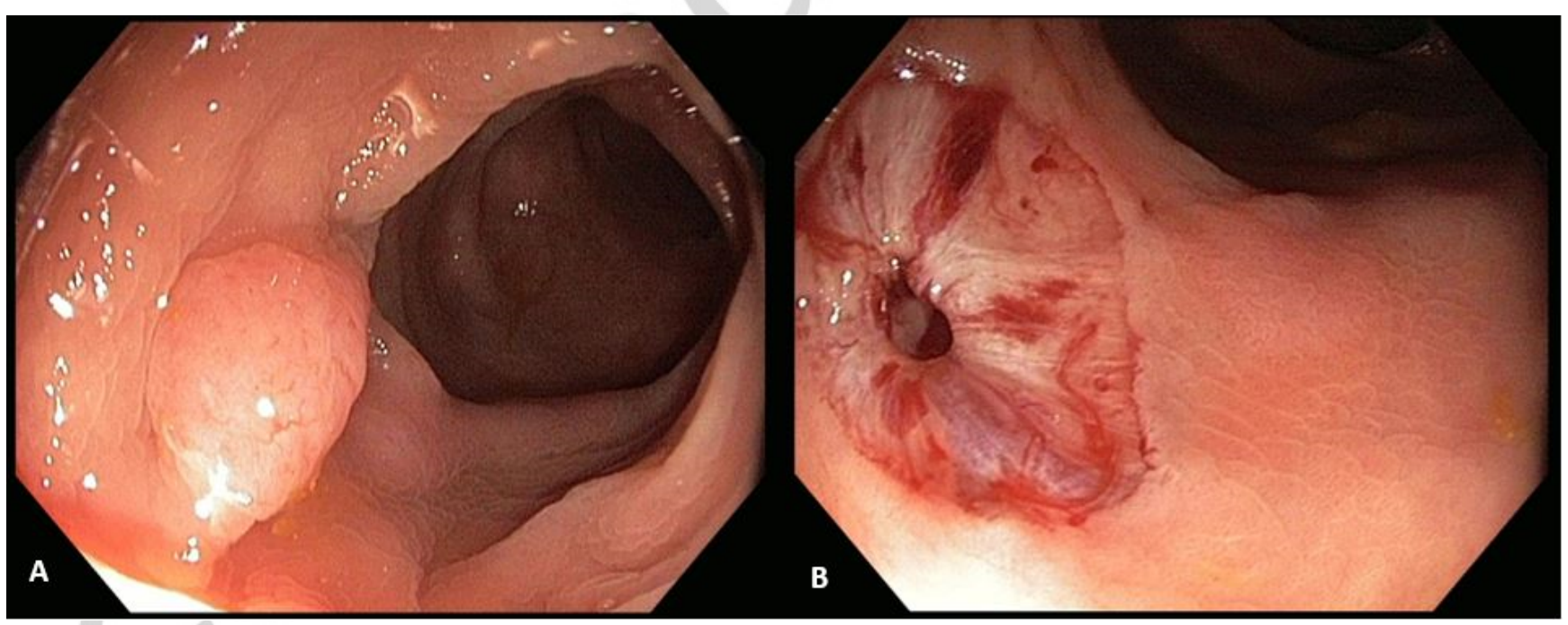

Figure 1. (A) Hyperplastic polyp, $5 \mathrm{~mm}$ of diameter, elevated-plane (Paris Ila) in the proximal transverse colon. (B) Microperforation after cold loop endoscopic polypectomy in one fragment. 


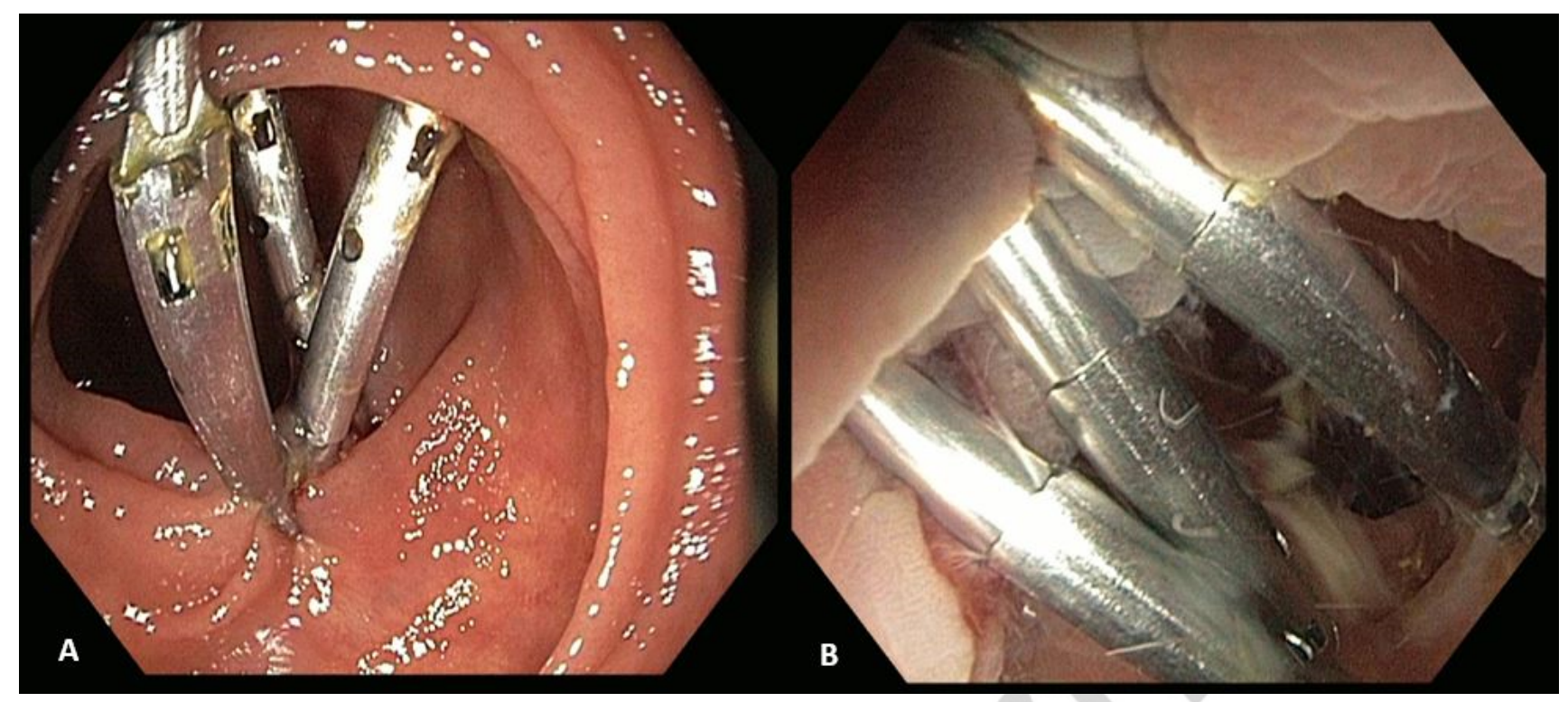

Figure 2. (A). Treatment of the microperforation with 3 endoscopic clips. (B) The colonic segment is filled with water without observing leakage through the perforation. 


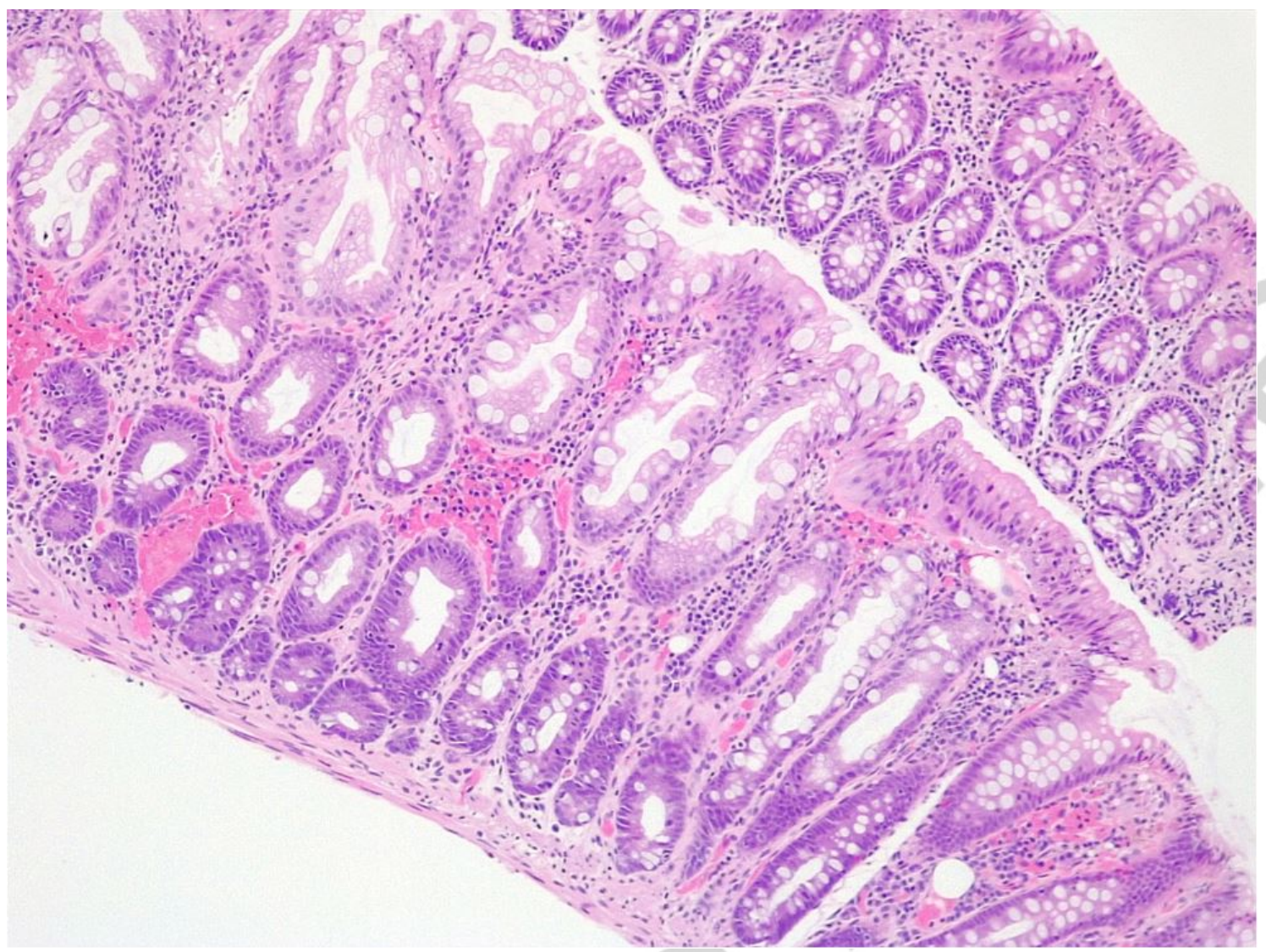

Figure 3. Hematoxylin eosin at 10X (100x magnification). Hyperplastic polyp wall with barely any histological changes, except for focal microbleeding. No portion of muscularis propria was found. 